\title{
SISTEMAS DE PRODUÇÃO DE FEIJÃO INTERCALADO COM CAFEEIRO ADENSADO RECÉM-PLANTADO
}

\author{
Production systems for bean associated with recently planted \\ dense coffee shrub cropping
}

Abner José de Carvalho', Messias José Bastos de Andrade², Rubens José Guimarães²

\begin{abstract}
RESUMO
Visando estudar o efeito do número de linhas e do nível de adubação do feijoeiro (Phaseolus vulgaris L.) no desempenho agronômico do consórcio do cafeeiro (Coffea arabica L.) com o feijoeiro, foi conduzido um experimento de campo na Universidade Federal de Lavras, em um Latossolo Vermelho distroférrico típico. O delineamento experimental foi blocos ao acaso com três repetições e esquema fatorial 4 x $4+1$, envolvendo quatro números de linhas intercalares de feijoeiro (uma, três, quatro e seis linhas por entrelinha de café) e quatro doses de adubação da leguminosa ( $0,50,100$ e $150 \%$ da adubação recomendada para o monocultivo,

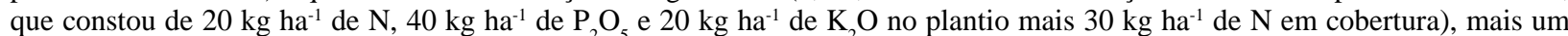
tratamento adicional (o monocultivo do cafeeiro ou do feijoeiro). O experimento foi conduzido em lavoura comercial da cv. Catucaí recém-plantada e a cv. de feijoeiro foi a BRS-MG-Talismã. No feijoeiro foram avaliados os estandes inicial e final, a altura de plantas e o rendimento de grãos com seus componentes primários (número de vagens por planta, número de grãos por vagem e massa média de 100 grãos). No cafeeiro as características avaliadas foram à emissão de pares de folhas e o incremento na altura de plantas e no diâmetro do caule, verificados entre a semeadura e a colheita do feijoeiro, além da mortalidade dos cafeeiros. Os resultados permitem concluir que o aumento do número de linhas intercalares de feijoeiro eleva o rendimento de grãos da leguminosa, mas reduz o incremento do diâmetro do caule do cafeeiro recém-plantado. A partir de quatro linhas de feijoeiro há tendência de aumento da mortalidade de plantas de café, principalmente na ausência de adubação da leguminosa. A adubação equivalente a até $150 \%$ da dose recomendada para o monocultivo do feijoeiro não influencia o rendimento de grãos da leguminosa, mas contribui para diminuir a mortalidade do cafeeiro recém-plantado quando se utiliza seis linhas intercalares de feijoeiro.
\end{abstract}

Termos para indexação: Culturas intercalares, consórcio café-feijoeiro, cultivo consorciado, Phaseolus vulgaris, Coffea arabica.

\begin{abstract}
A field experiment was carried out in a typical dystrophic Red Latosol at the campus of the Universidade Federal de Lavras, in order to study the effects of the row numbers and fertilization level of the bean plant (Phaseolus vulgaris L.) upon the agronomic performance of the coffee shrub (Coffea arabica L.) associated with bean plant. The experimental randomized block design was used with three replicates and factorial scheme $4 \times 4+1$, as involving four intercalary row numbers of the bean plant (one, three, four, and six lines by each inter row of coffee shrub) and four fertilization doses $(0,50,100$, and $150 \%$ from the fertilization recommended for monocropping, consisting of $20 \mathrm{~kg} \mathrm{ha}^{-1} \mathrm{~N}, 40 \mathrm{~kg} \mathrm{ha}^{-1} \mathrm{P}_{2} \mathrm{O}_{5}$ and $20 \mathrm{~kg} \mathrm{ha}^{-1} \mathrm{~K}_{2} \mathrm{O}$ at planting time plus $30 \mathrm{~kg} \mathrm{ha}^{-1} \mathrm{~N}$ side-dressing), as well as one more additional treatment (monocropping of either coffee shrub or bean plant). The assay was conducted in a recently planted commercial Catucaí farming, whereas the cultivar of the bean plant was BRS-MG-Talismã. The following variables were evaluated for the bean plant: the initial and final stands; the plant heights; and the productivity of the beans with its primary components (pod number per plant, graim number per pod, and average 100 graim weight). In coffee shrub, the characteristics under evaluation were the emission of leaf pairs and the increment in either plant height and stem diameter observed between sowing and harvesting the bean plant, as well as the mortality of the coffee shrubs. According to the results the increased number of the bean-plant intercalary rows rather rises the productivity of this leguminous, but reduces the increment of the stem diameter in the recently-planted coffee shrub. From four bean plant rows there is tendency to increased mortality of coffee shrubs, mainly in the absence of the leguminous fertilization. The fertilization up to $150 \%$ of the dose recommended to monocropping of the bean plant has no influence upon the productivity of this leguminous beans, although contributing to the reduced mortality in the recently-planted coffee shrub.
\end{abstract}

Index terms: Intercroppings, coffee shrub -bean plant association, associated cropping, Phaseolus vulgaris, Coffea arabica.

(Recebido para publicação em 19 de abril de 2005 e aprovado em 16 de fevereiro de 2006)

\section{INTRODUÇÃOO}

O Brasil é o maior produtor e exportador mundial de café (Coffea arabica L.) Na safra 2003-2004, a produção brasileira de café foi de cerca de 32 milhões de sacas, o que corresponde a, aproximadamente, $35 \%$ da produção mundial naquela safra (COFFEE BUSINESS, 2005). A importância econômica e social da cultura do feijão (Phaseolus vulgaris L.) para o Brasil também é inquestionável. $\mathrm{O}$ feijoeiro é cultivado nos mais variados 
tipos de solo, clima e sistemas de produção, tais como o cultivo solteiro, consorciado ou ainda intercalado com uma ou mais espécies (YOKOYAMA et al., 1996).

Desde o início da cafeicultura no Brasil utilizaramse culturas intercalares, principalmente nos primeiros anos de formação da lavoura, conforme relatam diversos autores (BEGAZO, 1984; CHEBABI, 1984; GUIMARÃES et al., 2002; MELLES et al., 1978, 1979; VIEIRA, 1985). Para Vieira (1985), a fase de implantação da lavoura cafeeira tem alto custo, devido ao grande dispêndio de insumos e mão-deobra exigidos na ocasião. Além disso, somente a partir do terceiro ano após a implantação a lavoura começará a dar retornos. Daí a importância das culturas intercalares: proporcionar renda imediata ao cafeicultor, ajudando-o a reduzir os custos de formação da lavoura. O sistema de produção, compreendido pelos tratos culturais, fitossanitários e adubações, tanto da cultura intercalar quanto do cafeeiro deve ser bem planejado para o sucesso do uso dessa prática (GUIMARÃES et al., 2002). Outros autores (CHAVES, 1977a, b; MELLES et al., 1979; VIEIRA, 1985) ainda chamam a atenção para possíveis prejuízos no desenvolvimento de cafeeiros novos e na produção de cafeeiros adultos consorciados com outras culturas, quando a adubação e/ou populações são inadequadas.

Buscou-se com este estudo, a partir de características avaliadas em ambas as culturas, determinar o número de linhas e a dose de adubação do feijoeiro que proporcionam maior produção de grãos da leguminosa em cultivo intercalar com cafeeiro recém-plantado, sem comprometer o seu desenvolvimento.

\section{MATERIAL E MÉTODOS}

O experimento de campo foi conduzido no Setor de Cafeicultura do Departamento de Agricultura (DAG) da Universidade Federal de Lavras (UFLA), na safra da seca de 2004. O solo das áreas experimentais foi classificado como Latossolo Vermelho distroférrico típico (EMBRAPA, 1999). A interpretação dos resultados das análises químicas do solo permitiu verificar que a fertilidade original do solo era boa, não sendo necessária nenhuma correção de acidez ou fertilidade nas áreas empregadas.

O delineamento experimental empregado para cada cultura foi o de blocos casualizados, com três repetições e esquema fatorial 4 × $4+1$, envolvendo quatro números de linhas intercalares de feijoeiro (uma, três, quatro e seis linhas por entrelinha de café) e quatro doses de adubação do feijoeiro intercalado $(0,50,100$ e $150 \%$ da adubação recomendada para o monocultivo), mais um tratamento adicional referente ao monocultivo. Nos sistemas consorciados, cada parcela consistia em $36 \mathrm{~m}^{2}$ de área total (6 $\mathrm{m}$ de comprimento e $6 \mathrm{~m}$ de largura, correspondentes a duas ruas de café), sendo considerada a área útil de $18 \mathrm{~m}^{2}$. No feijão em monocultivo, a área total foi de $24 \mathrm{~m}^{2}$, envolvendo oito linhas de $6 \mathrm{~m}$ de comprimento; neste caso a área útil da parcela foi de $12 \mathrm{~m}^{2}$, correspondentes às quatro linhas centrais de feijoeiro. As avaliações foram realizadas utilizando-se uma, três, quatro ou seis linhas de feijoeiro, de maneira a manter sempre a proporcionalidade entre o número de linhas de ambas as culturas, característica de cada tratamento. No caso do cafeeiro, tanto em consórcio quanto em monocultivo, as avaliações foram realizadas em quatro plantas previamente marcadas na linha central de cafeeiros de cada parcela, exceto o índice de mortalidade, que considerou todas as plantas pertencentes àquela linha.

As parcelas do cultivo intercalar e do monocultivo do café foram demarcadas em lavoura cafeeira comercial da cv Catucaí implantada em janeiro de 2004, no espaçamento de 3,0 m entre linhas e 0,60 m entre plantas. As parcelas do feijão em monocultivo foram instaladas em área contígua ao cafezal. Tanto no monocultivo como no cultivo intercalar, o feijoeiro, cv. BRS MG - Talismã, foi semeado em março de 2004, no espaçamento de $0,50 \mathrm{~m}$ entre linhas, utilizando-se 15 sementes por metro.

O preparo do solo das glebas utilizadas foi convencional. O plantio do feijoeiro foi realizado manualmente com a utilização de enxadas para o sulcamento das linhas e distribuição manual das sementes.

O cafeeiro foi adubado conforme recomendação oficial para o Estado de Minas Gerais (GUIMARÃES et al., 1999). A adubação de referência (100\%) do feijoeiro foi a recomendada oficialmente em Minas Gerais para o nível 2 de tecnologia (CHAGAS et al., 1999) e constou de $20 \mathrm{~kg}$ $\mathrm{ha}^{-1}$ de $\mathrm{N}, 40 \mathrm{~kg} \mathrm{ha}^{-1}$ de $\mathrm{P}_{2} \mathrm{O}_{5}$ e $20 \mathrm{~kg} \mathrm{ha}^{-1}$ de $\mathrm{K}_{2} \mathrm{O}$ no plantio mais $30 \mathrm{~kg} \mathrm{ha}^{-1}$ de $\mathrm{N}$ em cobertura. Os cultivos foram permanentemente monitorados e não foram necessárias quaisquer medidas de controle fitossanitário. O manejo das plantas daninhas foi realizado por capinas manuais.

No feijoeiro foram avaliados os estandes inicial e final, a altura média de plantas e o rendimento de grãos com seus componentes primários (número de vagens por planta, número de grãos por vagem e massa média de 100 grãos). Tanto massa média de 100 grãos, expressa em gramas, quanto o rendimento de grãos, expresso em kg ha-1, foram corrigidos para $13 \%$ de umidade. No cafeeiro foram avaliados a emissão de pares de folhas, o incremento na altura de planta e no diâmetro do caule, além da mortalidade de plantas. As avaliações no cafeeiro foram realizadas por 
ocasião da semeadura do feijoeiro e após a colheita do mesmo. Para a análise estatística foram considerados os dados referentes ao incremento verificado entre as duas avaliações.

Os dados foram submetidos à análise de variância (GOMES, 2000), utilizando-se o pacote computacional Sisvar (FERREIRA, 2000). As médias do tratamento adicional e do fatorial foram comparadas pelo teste $\mathrm{F}$. No caso de significância das fontes de variação número de linhas ou adubação, os efeitos foram estudados através de regressão, selecionando-se o modelo adequado para expressa-los por meio da significância do modelo e do valor do $\mathrm{R}^{2}$. Os dados referentes à mortalidade do cafeeiro foram transformados em $\sqrt{(x+1)}$ (GOMES, 2000).

\section{RESULTADOS E DISCUSSÃO}

\section{Características do feijoeiro}

A análise de variância dos dados relativos ao feijoeiro revelou que a fonte de variação adubação (A) influenciou significativamente apenas o estande inicial, enquanto o número de linhas intercalares de feijoeiro (NL) afetou os estandes inicial e final e o rendimento de grãos. A interação A x NL não se mostrou significativa para nenhuma das variáveis analisadas. O tratamento adicional diferiu da média do fatorial no que diz respeito aos estandes inicial e final e ao número de vagens por planta.

O incremento da adubação do feijoeiro causou ligeira redução do estande inicial (Figura 1), provavelmente devido ao aumento da concentração salina na rizosfera do feijoeiro.

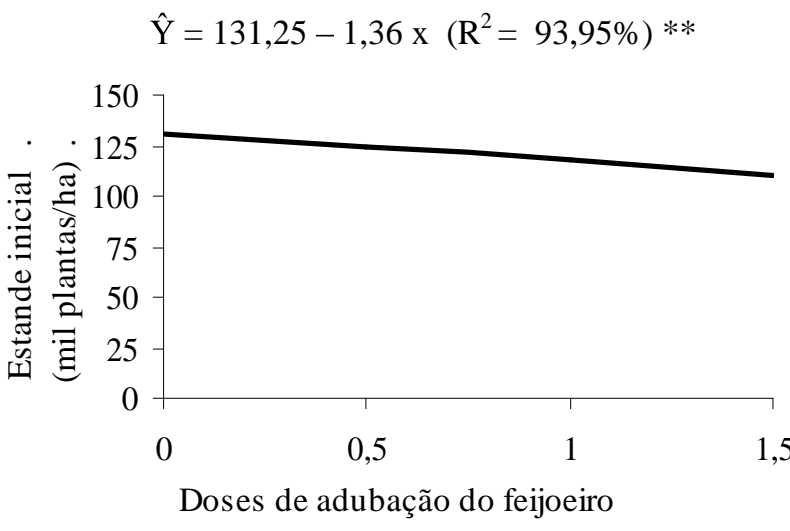

FIGURA 1 - Estande inicial do feijoeiro cv. Talismã intercalado ao cafeeiro recém-plantado, em função das doses de adubação da leguminosa. UFLA, Lavras - MG, 2004.
Este efeito negativo tem sido verificado por muitos autores, principalmente com o incremento da dose de N (ARAÚJO et al., 1994; RODRIGUES et al., 2002; SILVEIRA \& DAMASCENO, 1993; TEIXEIRA et al., 2000) e também da dose de K (ANDRADE \& RAMALHO, 1995). Este efeito, entretanto, não foi suficiente para se manifestar em diferenças no estande final. No entanto, os valores médios dos estandes inicial e final obtidos no fatorial foram significativamente inferiores aos do monocultivo.

$\mathrm{O}$ estande inicial do feijoeiro, como era esperado, aumentou linearmente com o incremento do número de linhas intercalares ao cafeeiro (Figura 2) e este efeito manifestou-se também no estande final (Figura 3). A população final de feijoeiros com seis linhas de feijão em consórcio foi de $192 \mathrm{mil}$ plantas por hectare, alcançando cerca de $87 \%$ da população de plantas do monocultivo, que foi de 220 mil plantas.

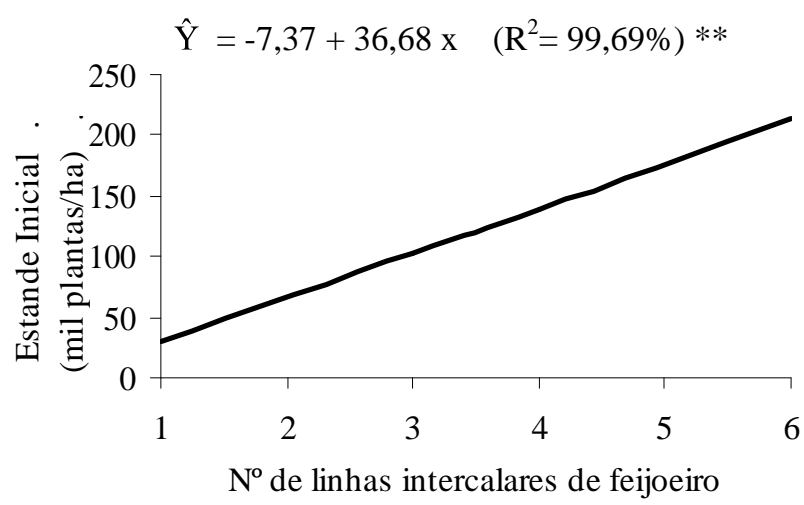

FIGURA 2 - Estande inicial do feijoeiro cv. Talismã intercalado ao cafeeiro recém-plantado, em função do número de linhas intercalares. UFLA, Lavras - MG, 2004.

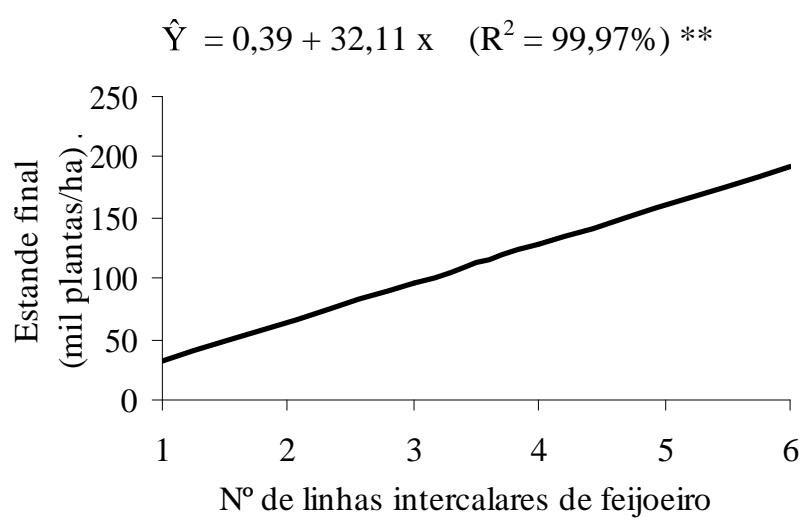

FIGURA 3 - Estande final do feijoeiro cv. Talismã intercalado ao cafeeiro recém-plantado, em função do número de linhas intercalares. UFLA, Lavras - MG, 2004. 
O número médio de vagens por planta do cultivo intercalar foi superior a do monocultivo do feijoeiro. Provavelmente o menor número de plantas no consórcio, aliado às adaptações do feijoeiro em cultivos consorciados (LOPES, 1988), tenha proporcionado certa compensação entre os componentes do rendimento. No presente ensaio isto ficou patente quando se comparou o monocultivo com a média do fatorial. Quando se analisaram os diferentes números de linhas de feijoeiro isto não ocorreu, devido às diferenças maiores entre as populações.

À medida que se aumentou o número de linhas intercalares ao café, o rendimento de grãos do feijoeiro elevou-se de forma quadrática, independentemente do nível de adubação (Figura 4).

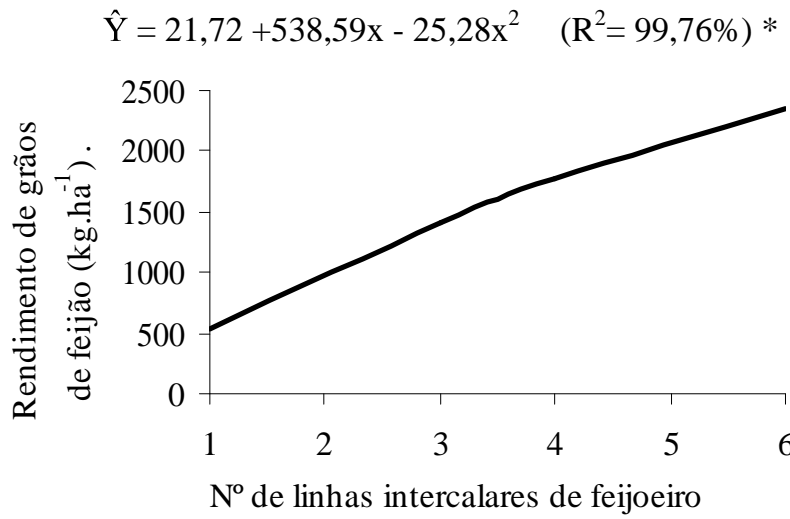

FIGURA 4 - Rendimento de grãos do feijoeiro cv. Talismã intercalado ao cafeeiro recém-plantado em função do número de linhas da leguminosa. UFLA, Lavras - MG, 2004.

O emprego de quatro linhas já havia superado o monocultivo, mas o uso de seis linhas de feijão propiciou rendimento médio de grãos que superou em cerca de $30 \%$ o rendimento do monocultivo. Este resultado pode ser explicado, em parte, pelo preparo de solo mais completo realizado por ocasião do plantio do café e que, certamente, beneficiou também o feijoeiro. Ajudam a explicar este fato, o maior estande final obtido (Figura 3) e o maior número de vagens/planta no cultivo intercalar.

É necessário ressaltar que as doses de adubação não influenciaram a maioria das características e o rendimento de grãos do feijoeiro intercalado, provavelmente em função da boa fertilidade inicial do solo, o qual permitiu, mesmo sem adubação, rendimento que não diferiu do emprego das doses recomendadas para a leguminosa, ou mesmo na presença adicional de $50 \%$ da dose recomendada. Este resultado, entretanto, deve ser interpretado com cuidado, haja vista que o incremento da adubação, mesmo não trazendo maiores rendimentos de feijão, pode ser vantajoso se compensar eventual competição nutricional entre as culturas consortes, ou seja, se evitar redução no desenvolvimento do cafeeiro. Como se trata de cultura recém-plantada, o efeito negativo desta competição só será evidenciado futuramente. Há que se considerar também que o cafeeiro poderá ser beneficiado futuramente por esta adubação, com o crescimento do sistema radicular.

\section{Características do cafeeiro}

A análise de variância dos dados relativos às características avaliadas no cafeeiro revelou que a emissão de pares de folhas e o aumento na altura de plantas não foram influenciados pelo número de linhas e pela dose de adubação do feijoeiro. $\mathrm{O}$ crescimento do diâmetro do caule do cafeeiro foi afetado significativamente pelo número de linhas intercalares de feijoeiro. A interação número de linhas $\mathrm{x}$ adubação afetou significativamente somente a mortalidade de plantas do cafeeiro. $\mathrm{O}$ contraste monocultivo do cafeeiro $\mathrm{x}$ consórcio não foi significativo em relação a nenhuma das variáveis estudadas, indicando que o comportamento do cafeeiro em monocultivo não diferiu da média do cafeeiro consorciado com o feijoeiro. Esta comparação, entretanto, tem caráter superficial e pode representar erro de interpretação, já que no fatorial, para todas as características avaliadas, as médias correspondem aos valores médios obtidos por todos os números de linhas e doses de adubação estudados.

$\mathrm{O}$ aumento do número de linhas intercalares de feijoeiro provocou, no período analisado, menor incremento no diâmetro do caule do cafeeiro (Figura 5), indicando que o uso de maior população do feijoeiro promoveu menor desenvolvimento em diâmetro do cafeeiro. Este resultado, pode ser atribuído à maior competição estabelecida pelo aumento da população da leguminosa. Trabalhos realizados em outras épocas (CHAVES, 1977a, 1978), estudando o efeito de culturas intercalares em cafezais com espaçamento tradicional (4 m entre linhas) não detectaram prejuízos ao incremento do diâmetro do caule do cafeeiro no primeiro ano de formação, quando o feijoeiro foi semeado a 1,0 $\mathrm{m}$ da linha de cafeeiro.

Há inclusive, resultados mais otimistas na literatura. Melles et al. (1978), trabalhando com as culturas de arroz, milho, soja, feijão e feijão-de-porco, nos dois primeiros anos de formação da lavoura cafeeira, observaram que a produção de café na primeira colheita foi maior em alguns tratamentos consorciados que no monocultivo do cafeeiro, talvez pela proteção contra ventos e pelo sombreamento promovidos

Ciênc. agrotec., Lavras, v. 31, n. 1, p. 133-139, jan./fev., 2007 
pela presença das culturas intercalares. Melles et al. (1979), trabalhando com as mesmas culturas intercaladas ao cafezal em espaçamento tradicional, concluíram que a utilização de até cinco linhas de feijoeiro nos dois primeiros anos de formação do cafeeiro proporcionou ganho em produtividade de café em relação ao seu monocultivo.

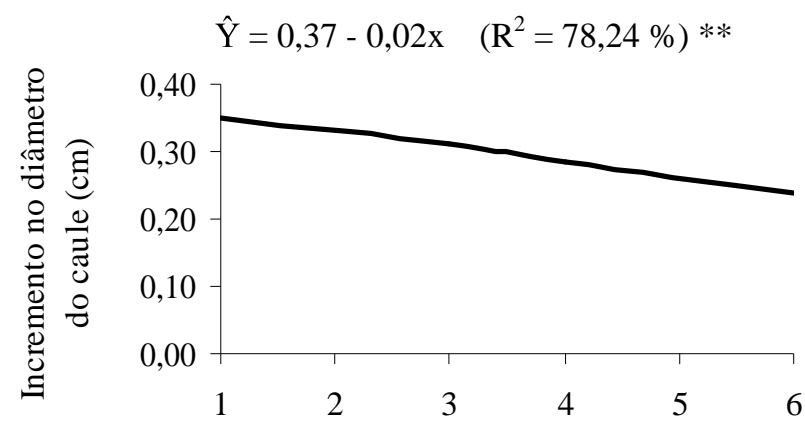

$\mathrm{N}^{\mathrm{o}}$ de linhas intercalares de feijoeiro

FIGURA 5 - Incremento no diâmetro do caule do cafeeiro cv. Catucaí recém-plantado em função do número de linhas intercalares do feijoeiro cv. Talismã. UFLA, Lavras - MG, 2004.

O estudo do efeito da interação NL x A sobre a mortalidade foi feito a partir de dois tipos de desdobramento. No primeiro, verificou-se o efeito do número de linhas em cada nível de adubação e constatou-se efeito significativo na dose de adubação 0 (Figura 6). Este resultado, apesar do baixo valor do $\mathrm{R}^{2}$ da equação apresentada, mostrou que a competição do feijoeiro pode ser exercida com maior intensidade quando os fatores de crescimento, como a disponibilidade de nutrientes e água, são mais limitados.

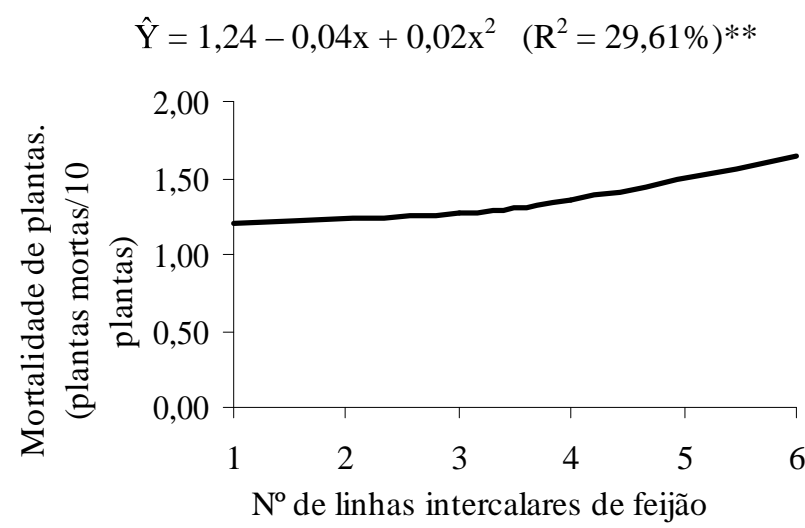

FIGURA 6 - Índice de mortalidade do cafeeiro cv. Catucaí recém-plantado em função do número de linhas intercalares e na ausência de adubação do feijoeiro. UFLA, Lavras MG, 2004.
Este efeito também foi verificado por Chebabi (1984) num ensaio em casa-de- vegetação, em que as culturas anuais de feijão, arroz, milho e soja, plantadas em alta densidade populacional em recipientes juntamente com mudas de cafeeiro, concorreram com a rubiácea, prejudicando o seu desenvolvimento em todas as características avaliadas. Santinato et al. (1976), por sua vez, observaram que o feijoeiro plantado a $0,50 \mathrm{~m}$ da linha do cafeeiro e adubado adequadamente, não concorreu com o cafeeiro por N, P, Ca e Mg.

No segundo desdobramento (adubação dentro de cada número de linhas), apurou-se efeito significativo nos casos de quatro e seis linhas intercalares (Figura 7). As diferenças verificadas, entretanto, apesar de significativas, foram de pequena magnitude e incoerentes, ora aumentando, ora reduzindo a mortalidade. Além disso, os valores do $\mathrm{R}^{2}$ foram relativamente baixos, indicando pequeno ajuste dos dados ao modelo matemático selecionado. A observação prática que pode ser inferida é a de que se deve adubar o feijoeiro quando intercalado ao cafeeiro. Apesar desta prática não elevar a produtividade do feijoeiro, diminui a mortalidade do cafeeiro, sobretudo quando se eleva o número de linhas intercalares.

$\begin{array}{lll}\text { Adubação dentro de } 4 \text { linhas } & & \hat{Y}=0,95+0,04 x \quad\left(\mathrm{R}^{2}=78,57 \%\right) * * \\ \text { Adubação dentro de } 6 \text { linhas } & \ldots . . & \hat{Y}=1,58-0,04 x \quad\left(R^{2}=69,98 \%\right) * *\end{array}$
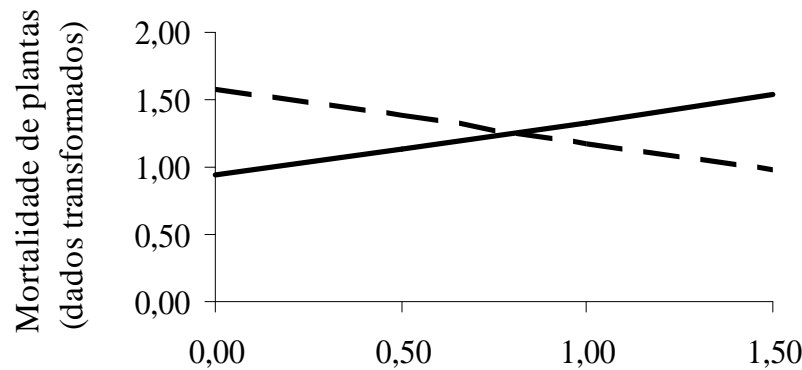

Doses de adubação do feijoeiro

FIGURA 7 - Índice de mortalidade do cafeeiro cv Catucaí em função das doses de adubação do feijoeiro cv Talismã, nos tratamentos com quatro e seis linhas intercalares. UFLA, Lavras - MG, 2004.

\section{CONCLUSÕES}

O aumento do número de linhas de feijoeiro cultivadas nas entrelinhas do cafezal recém-plantado eleva o rendimento de grãos da leguminosa, mas reduz o incremento do diâmetro do caule do cafeeiro. A partir de quatro linhas intercalares de feijoeiro, em cafeeiro com espaçamento de $3 \mathrm{~m}$ entre linhas, há tendência de aumento 
da mortalidade de plantas de café, principalmente na ausência de adubação da leguminosa.

A adubação equivalente a até $150 \%$ da dose recomendada para o monocultivo do feijoeiro $\left(20 \mathrm{~kg} \mathrm{ha}^{-1}\right.$ de $\mathrm{N}, 40 \mathrm{~kg} \mathrm{ha}^{-1}$ de $\mathrm{P}_{2} \mathrm{O}_{5}$ e $20 \mathrm{~kg} \mathrm{ha}^{-1}$ de $\mathrm{K}_{2} \mathrm{O}$ no plantio mais $30 \mathrm{~kg} \mathrm{ha}^{-1}$ de $\mathrm{N}$ em cobertura) não influencia o rendimento de grãos da leguminosa intercalada ao cafezal, mas, quando se utiliza seis linhas intercalares de feijoeiro por entrelinha de café no espaçamento de $3 \mathrm{~m}$ entre linhas, contribui para diminuir a mortalidade do cafeeiro recém-plantado.

\section{REFERÊNCIAS BIBLIOGRÁFICAS}

ANDRADE, M. J. B. de; RAMALHO, M. A. P. Cultura do feijoeiro. In: EMPRESA BRASILEIRA DE PESQUISA AGROPECUÁRIA. Curso de atualização técnica dos engenheiros agrônomos do Banco de Brasil, módulo sudeste. Sete Lagoas, 1995. 97 p.

ARAÚJO, G. A. de A.; VIEIRA, C.; MIRANDA, G. V. Efeito da época de aplicação do adubo nitrogenado em cobertura sobre o rendimento do feijão, no período de outono-inverno. Revista Ceres, Viçosa, v. 14, n. 236, p. 442450, jul./ago. 1994.

BEGAZO, J. C. E. O. Considerações sobre o feijão como cultura consorciada do cafezal e mandiocal. Informe Agropecuário, Belo Horizonte, v. 10, n. 118, p. 50-51, out. 1984.

CHAGAS, J. M.; BRAGA, J. M.; VIEIRA, C.; SALGADO, L. T.; JUNQUEIRA NETO, A.; ARAÚJO, G. A. A.; ANDRADE, M. J. B. de; LANA, R. M. Q.; RIBEIRO, A. C. Feijão. In: RIBEIRO, A. C.; GUIMARÃES, P. T. G.; ALVAREZ, V. H. Recomendações para o uso de corretivos e fertilizantes em Minas Gerais: $5^{\text {a }}$ aproximação. Viçosa: CFSEMG, 1999. p. 306-307.

CHAVES, J. C. D. Estudos de culturas intercalares na formação de lavouras cafeeira. In: CONGRESSO BRASILEIRO DE PESQUISAS CAFEEIRAS, 5., 1977, Guaraparí. Resumos... Rio de Janeiro: IBC-GERCA, 1977a. p. 55-57.

CHAVES, J. C. D. Estudos de culturas intercalares em cafezais recepados no Paraná. In: CONGRESSO BRASILEIRO DE PESQUISAS CAFEEIRAS, 5., 1977, Guaraparí. Resumos... Rio de Janeiro: IBC-GERCA, 1977b. p. 62-64.

CHAVES, J. C. D. Estudos de culturas intercalares em cafezais recepados e em formação. In: CONGRESSO BRASILEIRO DE PESQUISAS CAFEEIRAS, 6., 1978,
Ribeirão Preto. Resumos... Rio de Janeiro: IBC-GERCA, 1978. p. 125-127.

CHEBABI, M. A. A. Influência da competição nutricional de culturas anuais (arroz, milho, feijão e soja), no desenvolvimento do cafeeiro(Coffea arabicaL.). 1984. 72 f. Dissertação (Mestrado em fitotecnia) - Escola Superior de Agricultura de Lavras, Lavras, 1984.

COFFEE BUSINESS. Anuário estatístico do café 20042005. Rio de janeiro, 2005. 130 p.

EMPRESA BRASILEIRA DE PESQUISA AGROPECUÁRIA. Sistema brasileiro de classificação de solos. Brasília, 1999. 412 p.

FERREIRA, D. F. Análise estatística por meio do SISVAR para Windows versão 4.0. In: REUNIÃO ANUAL DA REGIÃO BRASILEIRA DA SOCIEDADE INTERNACIONAL DE BIOMETRIA, 45., 2000, São Carlos, SP. Programa e Resumo... São Carlos: UFSCar, 2000. p. 235.

GOMES, F. P. Curso de estatística experimental. 14. ed. Piracicaba: ESALQ, 2000. 467 p.

GUIMARÃES, P. T. G.; GARCIA, A. W. R.; ALVAREZ, V. H.; PREZOTTI, L. C.; VIANA, A. S.; MIGUEL, A. E.; MALAVOLTA, E.; CORRÊA, J. B.; LOPES, A. S.; NOGUEIRA, F. D.; MONTEIRO, A. V. C.; OLIVEIRA, J. A. de. Cafeeiro. In: RIBEIRO, A. C.; GUIMARÃES, P. T. G.; ALVAREZ, V. H. Recomendações para o uso de corretivos e fertilizantes em Minas Gerais: $5^{\text {a }}$ aproximação. Viçosa: CFSEMG, 1999. p. 289-302.

GUIMARÃES, R. J.; MENDES, A. N. G.; SOUZA, C. A. S. Culturas intercalares. In: Cafeicultura. Lavras: Indi, 2002. p. 247-257.

LOPES, N. F. Adaptabilidade fisiológica ao consórcio. In: ZIMMERMANN, M. J. de O.; ROCHA, M.; YAMADA, T. Cultura do feijoeiro: fatores que afetam a produtividade. Piracicaba: ABPPF, 1988. p. 375-395.

MELLES, C. C. A.; GUIMARÃES, P. T. G.; NACIF, A. P.; SILVA, C. M. da; CARVALHO, M. M. de; ANDRADE, M. A. de. Efeito de culturas intercalares na formação do cafeeiro. In: CONGRESSO BRASILEIRO DE PESQUISAS CAFEEIRAS, 6., 1978, Ribeirão Preto. Resumos... Rio de Janeiro: IBC-GERCA, 1978. p. 225-226. 
MELLES, C. C. A.; GUIMARÃES, P. T. G.; NACIF, A. P.; SILVA, C. M. da; CARVALHO, M. M. de; ANDRADE, M. A. de. Efeito de culturas intercalares na formação do cafeeiro. In: CONGRESSO BRASILEIRO DE PESQUISAS CAFEEIRAS, 7., 1979, Araxá. Resumos... Rio de Janeiro: IBC-GERCA, 1979. p. 174-175.

RODRIGUES, J. R. de M.; ANDRADE, M. J. B. de; CARVALHO, J. G. de; MORAIS, A. R. de; REZENDE, P. M. de. População de plantas e rendimento de grãos do feijoeiro em função de doses de nitrogênio e fósforo. Ciência e Agrotecnologia, Lavras, v. 26, n. 6, p. 12181227, nov./dez. 2002.

SANTINATO, R.; MIGUEL, A. E.; OLIVEIRA, J. A.; BARROS, A. V. Feijão como cultura intercalar nos dois primeiros anos de formação de cafezal. In: CONGRESSO BRASILEIRO DE PESQUISAS CAFEEIRAS, 4., 1976, Caxambú. Resumos... Rio de Janeiro: IBC-GERCA, 1976. p. 243-245.
SILVEIRA, P. M. da; DAMASCENO, M. A. Doses e parcelamento de $\mathrm{K}$ e de $\mathrm{N}$ na cultura do feijoeiro irrigado. Pesquisa Agropecuária Brasileira, Brasília, v. 28, n. 11, p. 1269-1276, nov. 1993.

TEIXEIRA, I. R.; ANDRADE, M. J. B. de; CARVALHO, J. G.; MORAIS, A. R.; CORREAA, J. B. D. Resposta do feijoeiro (Phaseolus vulgaris L. cv. Pérola) a diferentes densidades de semeadura e doses de nitrogênio. Ciência e Agrotecnologia, Lavras, v. 24, n. 2, p. 399-408, abr./jun. 2000.

VIEIRA, C. $O$ feijão em cultivos consorciados. Viçosa: UFV, 1985. $134 \mathrm{p}$.

YOKOYAMA, L. P.; BANNO, K.; KLUTHCOUSKI, J. Aspectos sócioeconômicos da cultura. In: ARAÙJO, R. S. et al. Cultura do feijoeiro comum no Brasil. Piracicaba: ABPPF, 1996. p. 1-21. 